\title{
TIẾP CẬN CDIO ĐỂ NÂNG CAO CHẤT LƯợNG ĐÀO TẠO THẠC SĨ NGÀNH CÔNG TÁC XÃ HộI TẠI TRƯờNG ĐẠI HỌC THỦ DẦU MộT
}

\author{
Ngô Hồng Điệp ${ }^{(*)}$, Dương Hiền Hạnh ${ }^{(*)}$ \\ Tiến sĩ. Truờng Đại học Thủ Dầu Một. Email: diepnh@tdmu.edu.vn
}

DOI: $10.37550 /$ tdmu.CFR/2021.01.112

\section{Tóm tắt}

Giáo dục thế kỷ XXI được xem là một cuộc cách mạng trong bối cảnh toàn cầu hoá (TCH), giáo dục để con người trương thành, và giáo dục bậc cao học vìa là co hộ vìa là thách thức đối với các truờng đại học. Thiết kế một chuơng trình đào tạo làm sao để đảm bảo chất lương đầu ra phù hợp với tiêu chí của nhà truờng, của quốc gia và quốc tế, đào tạo con người có đầy đủ phẩm chất đạo đức nghề, năng lục làm việc chuyên nghiệp và khả năng nghiên cưu độc lập đối với chuơng trình đào tạo thạc sĩ Công tác xã hội (CTXH) là một thách thức rất lớn. Tiếp cận xây dựng chuơng trình theo CIDO là một phương pháp tiếp cận khoa hoc, hiện đại và có tính đảm bảo chất lương cao đáp ứng với nhu cầu phát triển nguồn nhân lục hiện nay. Điểm mạnh của chuoong trình đào tạo CTXH được xây dụng dựa trên chuẩn đầu ra phù hợp với muc tiêu đào tạo cho nguời học nâng cao tay nghề CTXH, có khả năng quản trị và nghiên cúu độc lập trong chuyên ngành CTXH. Điểm mạnh trong chưong trình khoá 2020-2022 còn được nhấn mạnh về chính sách hố trọ học viên nghiên cứu khoa học độc lập có kinh phí và chính sách khen thương quy định bằng văn bản.

Tù khoá: Chương trình đào tạo thạc sĩ CTXH, tiếp cận, chuẩn CDIO.

\section{1. Đặt vấn đề}

Chương trình đào tạo thạc sĩ CTXH tại trường đại học Thủ Dầu Một là một trong những chương trình đào tạo thạc sĩ trong giai đoạn đầu từ năm 2016, đến nay chương trình cũng đang được điều chỉnh và xây dựng lại theo xu hướng tiếp cận hiện đại đáp ứng chuẩn đầu ra theo CIDO với mục đích xây dựng chương trình chuẩn, đào tạo đạt mục tiêu và hướng đến mục đích đào tạo nguồn nhân lực chất lượng cao cho tỉnh Bình Dương và khu vực.

\subsection{Cuộc cạnh tranh chất xám trong chuơng trình giáo dục cao học CTXH}

Giáo duc toàn cầu: Diễn biến của nền giáo dục toàn cầu hoá mỗi ngày gần hơn đối với Việt Nam dù ta có muốn hay không muốn thì sự hội nhập là khách quan là nhu cầu là chiến lược cho phát triển nói chung của một quốc gia. Văn hoá ngày một trở nên quan trọng trong thế giới toàn cầu, nó mang người ta đến với nhau, hiểu nhau, hợp tác với nhau hay 
cũng chính nó sẽ chia rẽ nhau, vậy thì người dân thời hiện đạị phải học để hội nhập, học để hợp tác và tồn tại. Cho nên vai trò của các trường học là rất quan trọng đặc biệt là vai trò của trường đại học tại Việt Nam hiện nay.

Cuộc cạnh tranh chất xám ở các truờng đại học: Xu hướng tăng tốc phương pháp tiếp cận trong giáo dục ở thế kỷ 21 hiện nay là "Khả năng tiếp cận của đại chúng; tăng cuờng dựa vào nguyên tắc thực tài; và áp dụng công nghệ" được xem là chiến lược chủ chốt và chính nhờ $\mathrm{TCH}$ mà việc tăng tốc này vượt trội nhanh chóng, giáo dục dần được xem là lĩnh vực thương mại, đầu tư, cung cấp dịch vụ chất lượng cho người học và chịu trách nhiệm với người học. Nhìn nhận từ thực tế hiện nay thì trường đại học phải có sự thay đổi trong phương pháp tiếp cận dạy và học. Phương pháp tiếp cận đúng đắn là yếu tố quyết định sự thành công hay thất bại trong xu hướng cạnh tranh toàn cầu.

Trường Đại học Thủ Dầu Một dù mới hơn 10 năm tuổi nhưng điều thuận lợi là sinh sau và kịp bắt được phương pháp tiếp cận mới của thời đại trong giáo dục, nhà trường đã nhanh chóng đưa ra những chiến lược thay đổi chất lượng giảng dạy, phương pháp giảng dạy để đáp ứng với nhu cầu thực tiễn về chất lượng nguồn nhân lực cho giai đoạn hội nhập của Việt Nam nói chung. Chương trình đào tạo CTXH tại trường Đại Học Thủ Dầu Một được xây dựng và phát triển từ năm 2016 cho đến nay, việc giảng dạy cao học ngành mới tại trường cũng là thách thức đối với đội ngũ giảng viên và lãnh đạo của chương trình. Chuẩn đầu ra của CDIO được xây dựng dựa trên nhu cầu thực tiễn của xã hội và định hướng chiến lược của nhà trường tập trung vào chiến lược "Nghiên cưu, ứng dụng và phuc $v u$ cộng dồng", các học viên trong chương trình tiếp nhận cách tiếp cận mới, quan điểm mới và mục tiêu mới trong quá trình chuyển đổi nền học thuật theo lối cũng sang tiếp cận theo CDIO. Việc thay đổi này mang tích cách mạng làm thay đổi cả hệ thống từ chương trình đào tạo, mục tiêu đào tạo, chuẩn đầu ra của chương trình và sự gắn kết của từng môn học rất chặt chẽ, đồng thời qua việc tiếp cận $\mathrm{CDIO}$ cũng thể hiện rõ sự bình đẳng giữa chương trình, người dạy, người học và nhà sử dụng nguồn nhân lực. Việc đào tạo những thành viên có bằng thạc sĩ có nghề (cả học thuật và thực nghiệm) là thách thức lớn mà trường đại học dù non trẻ vẫn quyết tâm đi đầu để dần hoàn thiện chương trình hướng đến hoạt động cao hơn, xa hơn là tiến tới đào tạo nguồn lực tiến sĩ cho ngành CTXH.

\subsection{Nhu cầu thục tiễn phải thay đổi}

Trường Đại học Thủ Dầu Một cũng như các trường khác trong cả nước đang tích cực thay đổi để bắt kịp thời đại $\mathrm{TCH}$ giáo dục, một trong những yếu tố quan trọng là thay đổi phương pháp dạy học truyền thống bằng phương pháp cải tiến mạnh mẽ bằng cách tiếp cận chương trình $\mathrm{CDIO}$, nhà trường đã mạnh dạn đầu tư và quyết tâm chuyển mình để nâng cao chất lượng giảng dạy từ bậc đại học đến cao học.

Chương trình đào tạo cao học ngành CTXH tiếp cận CDIO từ năm 2020, bắt đầu bằng sự thay đổi lớn trong việc mạnh dạn thay đổi chương trình bằng phương thức xây dựng mục tiêu và chuẩn đầu ra mang tính hệ thống phù hợp với chiến lược phát triển của nhà trường. Tính hệ thống chặt chẽ từ chương trình đào tạo đến đề cương chi tiết từng môn học đáp ứng nhu cầu chuẩn đầu ra của chương trình về kiến thức, kỹ năng và tinh thần tự chủ. Với đầu ra rõ ràng mang tính hệ thống thể hiện sự bình đẳng giữa cơ sở đào tạo với người học phục vụ chính cho 
đơn vị sử dụng nguồn nhân lực mà không phải đào tạo lại, năng lực thực tế của người học đáp ứng luôn với nhu cầu của nhà tuyển dụng nguồn lực theo nhu cầu.

Cùng với xu hướng hội nhập thì nhu cầu sử dụng lao động trong lĩnh vực giải quyết vấn đề xã hội là cần thiết, tuy nhiên với xu hướng hiện đại thì cạnh tranh chất lượng nguồn nhân lực hiện nay rất nhiều thách thức cả về năng lực chuyên môn và năng lực ngoại ngữ. Toàn cầu hoá, xuất hiện nhiều dòng dịch chuyển dân số, do đó nó hình thành nên những dịch vụ để đáp ứng cho nhu cầu của người tại chỗ và người nơi khác đến, chẳng hạn trong nước đã có nhiều đơn vị chăm sóc người cao tuổi, dạy học, các tổ chức cộng đồng đang phục vụ cho đối tượng là người nước ngoài. Vậy nhân viên $\mathrm{CTXH}$ là thực sự cần, nhưng yếu tố ngoại ngữ là điều kiện tiên quyết để làm việc. Cho nên đầu ra của chương trình CTXH ngoài kỹ năng thực hiện chuyên môn, kỹ năng nghiên cứu khoa học thì cần phải đạt tiêu chuẩn của giao tiếp bằng ít nhất một ngoại ngữ là vô cùng cần thiết, đây cũng là cơ hội và thách thức cho người học để có thể tham gia thị trường lao động chất lượng cao trong bối cảnh TCH hiện nay.

\subsection{Một số nguyên tác nhằm phát huy chất lự̣ng đào tạo thạc sĩ CTXH tại} Truò̀ng đại học Thủ Dầu Một

Chương trình đạo tạo thạc sĩ CTXH được xây dựng dựa trên một số tiêu chuẩn sau: So sánh đối chiếu với chuẩn đạo tạo của quốc gia ở bậc 7: đầu vào thuộc bậc đại học được đào tạo thêm 60 tín chỉ và được cấp bằng thạc sĩ và mục tiêu đào tạo người học có kỹ năng và kiến thức chuyên sâu hơn trong ngành $\mathrm{CTXH}$, trở thành những nhà nghiên cứu, quản lý trong CTXH trong thời gian hai năm.

So với chương trình bậc đại học đào tạo tập trung vào ứng dụng nghề CTXH thì chương trình đào tạo bậc thạc sĩ áp dụng tri thức vào nghiên cứu khoa học cũng được xem là trọng điểm của chương trình đào tạo, người học phải thực hành được nghề CTXH, có thể thấy được ưu điểm của chương trình cao học với 23 tín chỉ thực hành (bao gồm luận văn) trong toàn chương trình đào tạo.

Hướng đến mục tiêu hội nhập, chương trình cao học CTXH được thiết kế một học phần cực kỳ quan trọng: Thực tế có yếu tố nước ngoài, môn học này giúp học viên tiếp cận môi trường quản lý, thực hành $\mathrm{CTXH}$ tại các quốc gia có ngành $\mathrm{CTXH}$ phát triển. Học viên có cơ hội so sánh, học hỏi và rút ra bài học kinh nghiệm giữa hai môi trường thực hiện CTXH khác nhau có tính quốc tế.

Tóm lại: Chương trình Thạc sĩ CTXH so với chương trình đào tạo đại học CTXH được nâng lên một tầm mới ở lĩnh vực nghiên cứu khoa học chuyên ngành, thao tác thông thạo bởi cách thiết kế chương trình mang tính tích hợp và hệ thống và tập trung vào nghiên cứu ứng dụng chuyên ngành.

\section{Trình bày trường hợp phát triển chương trình đào tạo thạc sĩ CTXH theo CDIO}

Chương trình đào tạo giảng dạy vừa phản ánh nội dung đào tạo vừa là bản văn, bản thiết kế thể hiện tổng thể các thành phần của quá trình đào tạo. Chương trình đào tạo Thạc 
sĩ CTXH có cấu trúc cơ bản theo quan điểm của Tyler (1949), những yếu tố cần phải có như sau:

- Mục tiêu đào tạo

- Chuẩn đầu ra CTĐT

-Ý tưởng thiết kế CTĐT

- Khung CTÐT

- Ma trận các môn học

- Đề cương môn học

\subsection{Lý thuyết tiếp cận xây dụng chương trình đào tạo 2020-2022}

Theo quan điểm của Omstein và Hunkins (1988) cho rằng: Cách tiếp cận chuoong trình phản ánh một quan điểm xoay quanh việc thiết lập chương trình, các lĩnh vực của chuơng trình và nhũng nguyên tắc về lý thuyết và thực hành của chuoong trình [2].

Chọn lựa cách thức Tiếp cận mục tiêu (Objective Approach), chương trình đào tạo Thạc sĩ CTXH được thiết kế xuất phát từ mục tiêu đào tạo. Chương trình thể hiện cả quá trình đào tạo bao gồm: mục tiêu, nội dung, phương pháp, quy trình, đánh giá. Tiếp cận này tập trung vào mục tiêu được xác định rõ ràng, cụ thể theo thang đo Bloom để lượng hoá được và xây dựng theo chuẩn CDIO.

\subsection{Quan điểm xây dụng chương trình cao học CTXH theo CDIO}

Khởi nguồn chương trình giáo dục tiếp cận theo CDIO thuộc ngành khoa học kỹ thuật đáp ứng nhu cầu cải cách giáo dục đặt ra, phương pháp tiếp cận CIDO là sự kết hợp những quy trình mang tính toàn diện và có khả năng ứng dụng rộng rãi để cải tiến chương trình đào tạo, chất lượng giảng dạy, học tập, không gian làm việc và quy trình đánh giá và thay đổi chặt chẽ [4]. Dựa trên quan điểm tiếp cận CDIO của ngành kỹ thuật ban đầu thì chuyên ngành khối khoa học xã hội như CTXH cùng áp dụng phương pháp tiếp cận này vào việc xây dựng chương trình cao học. Đây là kiểu chương trình đào tạo tích hợp, với phương pháp tiếp cận mang tính hệ thống với những đặc tính như sau:

- Chương trình đào tạo được tổ chức xoay quanh các chuyên ngành, các chuyên ngành được kết nối và hỗ trợ lẫn nhau.

- Chuẩn đầu ra của chương trình được chuyển tải có hệ thống thành các chuẩn đầu ra trong từng môn học, từng hoạt động học tập để đảm bảo học viên tốt nghiệp đạt chuẩn đầu ra của chương trình đào tạo.

- Thiết kế chương trình có kế hoạch rõ ràng được toàn thể giảng viên của chương trình tiếp cận và làm chủ.

Đào tạo theo mô hình CDIO mang lại là nhiều lợi ích, trong đó thể hiện rõ nét ở lĩnh vực gắn kết được cơ sở đào tạo với yêu cầu của người tuyển dụng, từ đó thu hẹp khoảng cách giữa đào tạo của nhà trường và yêu cầu của nhà sử dụng nguồn nhân lực, tiếp cận CDIO trong giảng dạy còn giúp người học phát triển toàn diện với các "kĩ năng cứng" và "kĩ năng mềm", từng bước phát hiện ra năng lực của bản thân và có cơ hội lựa chọn mô 
hình học thuật và sáng tạo cho bản thân. Bên cạnh đó thông qua chương trình được thiết kế theo chuẩn CDIO cũng giúp nâng cao năng lực của giảng viên. Có thể xác nhận lần nữa đối với chương trình được xây dựng dựa trên chuẩn $\mathrm{CDIO}$ là để đảm bảo hai tiêu chí quan trọng: tính khoa học, và tính thực tiễn.

Xây dựng chương trình dựa trên chuẩn CDIO với mục tiêu cụ thể là: (1) Nắm vững kiến thức chuyên sâu; (2) Có khả năng kiến tạo sản phẩm; (3) Hiểu rõ giá trị quản lý cùng với sự tác động to lớn của việc nghiên cứu đẩy mạnh sự phát triển của công nghệ.

CDIO mang tính tích hợp và chủ động: Cách thức tiếp cận của chương trình giảng dạy được xây dựng trên chuẩn CDIO là người học sẽ học được các kiến thức/kỹ năng cho chính cá nhân của họ, và chính những kiến thức/kỹ năng học được đó sẽ được người học sử dụng vào việc phục vụ cho công việc, cho xã hội. Những kỹ năng cơ bản như: giao tiếp, kỹ năng xây dựng hệ thống, kỹ năng kiến tạo nên các sản phẩm...

\subsection{Chuẩn đầu ra mang tính công bằng trong hoạt động dạy và học}

Xây dựng đề cương môn học theo chuẩn đầu ra của chương trình mang tính công bằng đối với người học và người dạy. Học viên được cung cấp thông tin về môn học cụ thể, rõ ràng và chi tiết. Đảm bảo nội dung học theo chương trình và trong quá trình học người học chủ động. Trong đề cương chương trình thể hiện các tiêu chí đánh giá điểm quá trình, điểm giữa kỳ và cuối kỳ với những tiêu chí cụ thể. Đối với khoa học xã hội, thang đo để chấm điểm mang tính tương đối vì thế có Rubric đánh giá sẽ cụ thể hoá chi tiết nội dung kết quả làm bài của học viên. Đây là điểm tiến bộ của đề cương chi tiết được thiết kế theo chuẩn CDIO. Xem chuẩn đầu ra của chương trình đào tạo thạc sĩ CTXH:

Chuẩn đầu ra của chương trình: sau khi hoàn tất chương trình học học viên cần đạt:

\begin{tabular}{|c|c|}
\hline $\begin{array}{l}\text { Kiến } \\
\text { chung }\end{array}$ & $\begin{array}{l}\text { ELO1. Vận dụng được những kiến thức cơ bản về Triết học, Trách nhiềm xã ã } \\
\text { hội, Phương pháp nghiên cứu khoa học từ cơ bản đến nâng cao làm nền tảng } \\
\text { tiếp thu và vận dụng kiến thức cơ sở và chuyên sâu của ngành CTXH }\end{array}$ \\
\hline \multirow[t]{3}{*}{$\begin{array}{l}\text { Kiến thức co } \\
\text { sở và chuyên } \\
\text { ngành }\end{array}$} & $\begin{array}{l}\text { ELO2. Vận dụng kiến thức cơ sở ngành và chuyên ngành để phân tích thực trạng } \\
\text { những vấn đề xã hội, thiết kế mô hình can thiệp giải quyết vấn đề đối với công tác } \\
\text { xã hội cá nhân, công tác xã hội nhóm và mô hình dự án phát triển cộng đồng. }\end{array}$ \\
\hline & $\begin{array}{l}\text { ELO03. Vận dụng kiến thức thực tiễn qua hình thức thực hành, thực tế, tham } \\
\text { quan học tập từ các mô hình CTXH tiên tiến trong và ngoài nước để nâng cao } \\
\text { kỹ năng nghề nghiệp và quản trị dịch vụ CTXH. }\end{array}$ \\
\hline & $\begin{array}{l}\text { ELO04. Tổng hợp kiến thức chuyên ngành, phương pháp luận và phương pháp } \\
\text { nghiên cứu CTXH để thực hiện nghiên cứu thành công đề tài khoa học chât } \\
\text { lượng và có tính ứng dụng phù hợp với chuyên ngành } \mathrm{CTXH} \text {. }\end{array}$ \\
\hline $\begin{array}{l}\text { Kĩ } \\
\text { chung }\end{array}$ & $\begin{array}{l}\text { ELO 05. Vận dụng ngoại ngữ trong việc giao tiếp, trình bày, tham khảo tài liệu } \\
\text { để phục vụ cho công việc học tập của học viên }\end{array}$ \\
\hline
\end{tabular}




\begin{tabular}{|c|c|}
\hline & $\begin{array}{l}\text { ELO 06. Tổng hợp các kỹ năng giao tiếp, làm việc nhóm, lãnh đạo, lập kế } \\
\text { hoạch, kỹ năng sử dụng công nghệ thông tin nhằm xây dựng mạng lưới phục vụ } \\
\text { cho công việc của người học. }\end{array}$ \\
\hline \multirow[t]{2}{*}{$\begin{array}{l}\text { Kỹ năng } \\
\text { chuyên môn }\end{array}$} & $\begin{array}{l}\text { ELO 07. Vận dụng kỹ năng chuyên sâu của CTXH ứng dụng trong các mô } \\
\text { hình can thiệp giải quyết vấn đề cá nhân, nhóm và cộng đồng }\end{array}$ \\
\hline & $\begin{array}{l}\text { EL08. Tổng hợp kỹ thuật và phương pháp trong nghiên cứu CTXH để thực } \\
\text { hiện thành công luận văn thạc sĩ ứng dụng chuyên ngành CTXH }\end{array}$ \\
\hline \multirow[t]{2}{*}{$\begin{array}{l}\text { Tự chủ/trách } \\
\text { nhiệm }\end{array}$} & $\begin{array}{l}\text { ELO09. Thể hiện tinh thần chịu trách nhiệm và có khả năng dẫn dắt chuyên } \\
\text { môn để xử lý những vấn đề xã hội trong phạm vi tiếp cận ngành học. }\end{array}$ \\
\hline & $\begin{array}{l}\text { ELO10. Làm gương, thể hiện phẩm chất chính trị, đạo đức nghề, ý thức phục } \\
\text { vụ nhân dân, trách nhiệm công dân, tuân thủ pháp luật, ý thức rèn luyện sức } \\
\text { khỏe bản thân, khát vọng, tinh thần đổi mới sáng tạo, ý thức dấn thân phục vụ } \\
\text { vì lợi ích của thân chủ, ý thức học tấp suốt đời. }\end{array}$ \\
\hline
\end{tabular}

\subsection{Mô hình khung chuơng trình đào tạo Thạc sĩ CTXH 2020-2022}

\section{Phương pháp tiếp cận}

Theo quy định về quy chế đào tạo trình độ thạc sĩ của Bộ Giáo dục và Đào tạo như sau: Chưong trình đào tạo thạc sĩ thể hiện được muc tiêu đào tạo, quy định, chuẩn kiến thức, kỹ năng, phioong pháp, hình thức đào tạo, nội dung đào tạo, cách thức đánh giá kết quả đào tạo đối với mồi học phần đào tạo bậc thạc sĩ [5]

Xác định nhiệm vụ đào tạo ngành CTXH bậc Thạc sĩ tại Đại học Thủ Dầu Một là tất yếu, cùng với sự phát triển mạnh của các khu công nghiệp, những vấn đề xã hội phát sinh, nhu cầu cấp thiết cần có nguồn lực nhân viên $\mathrm{CTXH}$ có năng lực thực sự tham gia xã hội thực hiện nhiệm vụ CTXH chuyên nghiệp để giải quyết vấn đề xã hội đặt ra trong thế kỷ XXI thể hiện qua (1) Mô hình đào tạo Thạc sĩ CTXH được xây dựng mang tính hệ thống, (2) Học phần thực hành/thực tập rõ ràng và (3) Hoạt động nghiên cứu khoa học được đề ra nhờ vào chính sách nghiên cứu khoa học từ nhà trường. Sự đầu tư về chiến lược, chính sách nghiên cứu khoa học của nhà trường dành cho học viên cao học là một bước tiến rất lớn trong chương trình mới này, giúp hỗ trợ kỹ thuật, tài chính cho hoạt động đầu tra của toàn bộ chương trình.

Dưới đây là mô hình được thiết kế hướng đến chuẩn đầu ra của ngành CTXH bậc thạc sĩ năm 2020-2022, dựa trên nguyên tắc cải tiến triệt để từ chương trình 2018-2020

\section{Mô hình chương trình đào tạo thạc sĩ CTXH}

Các môn học được thiết kế phần lớn 3TC với phương thức dạy học tích hợp theo mô đun, mỗi môn học tập trung vào phương thức đọc tài liệu, phân tích, tổng hợp, viết tổng quan, lập kế hoạch và thực hành. Để đạt được mục tiêu của môn học, đòi hỏi giảng viên phải có chuyên môn chuyên ngành, thiết kế bài giảng chặt chẽ theo chuẩn đầu ra của CDIO tập trung vào mục tiêu của chương trình. Bên cạnh đó, người học phải chủ động nắm bắt thông tin, sử dụng E-learning như một phương tiện cần để tra cứu tư liệu, thông tin môn 
học và bài giảng. Người học cũng tập thích ứng với phương pháp học chủ động, có sự tham gia, tích cực trao đổi và phát huy phương pháp tranh luận, phản biện trong giờ học để nâng tầm nghề CTXH của chính bản thân trong suốt quá trình tham gia học tập tại trường. 


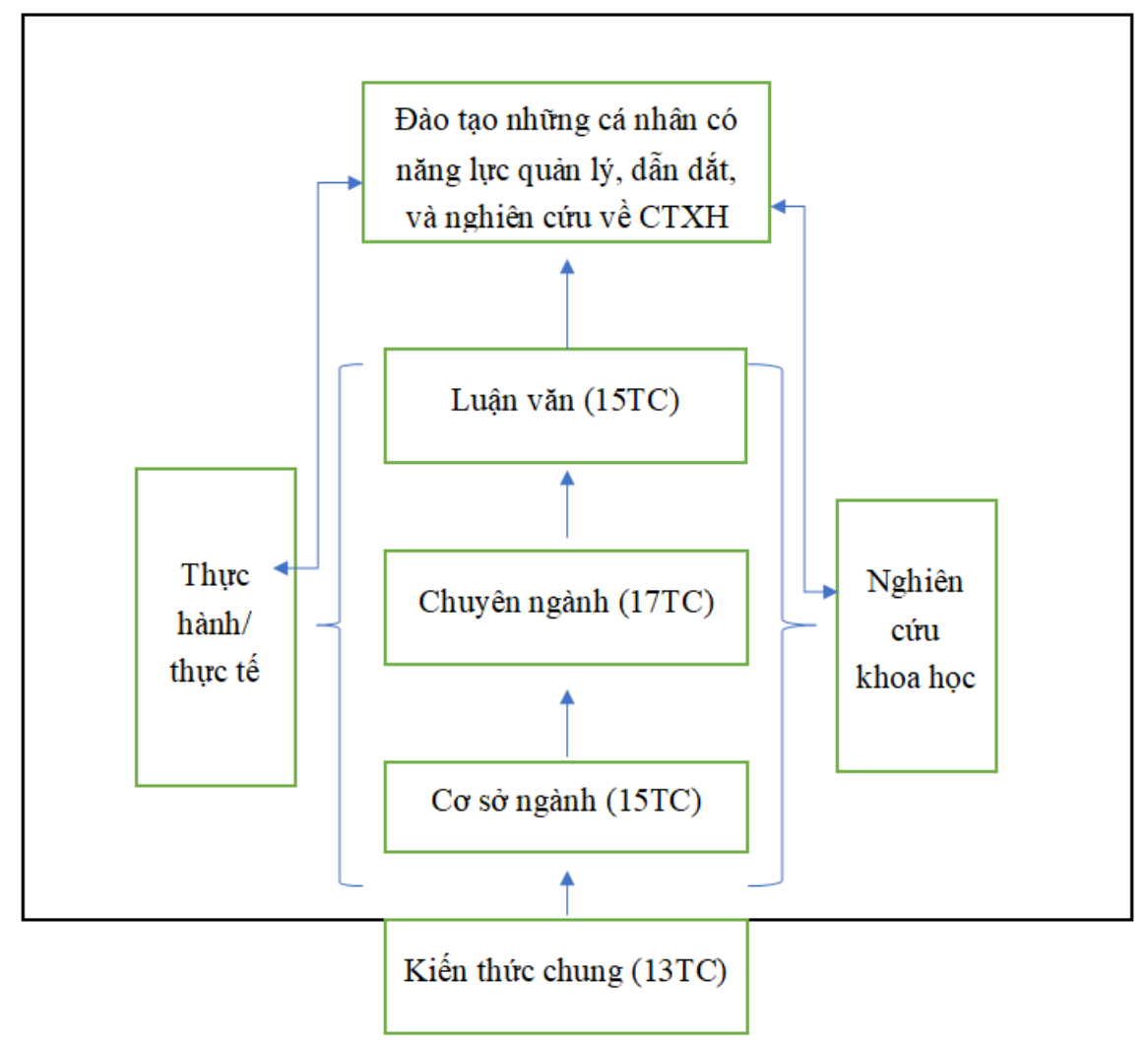

(Nguồn: Phát triển theo mô hình đào tạo Thạc sĩ CTXH 2020-2022)

Một số điểm nổi trội trong khung chương trình đào tạo mới:

\section{Hoạt động thục tập/thục tế có yếu tố nước ngoài}

Hoạt động thực hành, thực tế, có tổng số tín chỉ được thiết kế là 23TC/60TC. Đây là điểm mạnh của chương trình đào tạo Thạc sĩ $\mathrm{CTXH}$ của trường, và đặc điểm này cũng đáp ứng được mục tiêu, tầm nhìn của nhà trường là đào tạo theo hướng nghiên cứu và ứng dụng. Tính ứng dụng nghề $\mathrm{CTXH}$ là vô cùng quan trọng, so với nhiều chương trình khác tập trung vào nghiên cứu, nhưng đối với chương trình $\mathrm{CTXH}$ thì học viên phải vượt qua giai đoạn thực hành, nghiên cứu thực tiễn trong và ngoài nước (thực tập có yếu tố nước ngoài), áp dụng lý thuyết, phương pháp nghiên cứu liên ngành, xuyên ngành để có thể trở thành một nhà nghiên cứu độc lập sau khi toàn tất luận văn. Như vậy bản thân tác giả cho rằng đầu ra của ngành $\mathrm{CTXH}$ trong chương trình đào tạo thạc sĩ là khó, đòi hỏi người học phải nỗ lực nhiều hơn khi học chuyên ngành CTXH.

\section{Chính sách nghiên cứu khoa học của nhà trừ̀ng dành cho học viên cao học}

Theo kế hoạch thực hiện chiến lược phát triển trường đến năm 2030 do Chủ tịch hội đồng trường ký, ở mục 5 về hoạt động nghiên cứu khoa học của học viên cao học có quy định được tham gia chủ nhiệm đề tài cá nhân, được chuyển giao khoa học công nghệ và giải thưởng khoa học như một hạng mục quan trọng và cần thiết đối với hoạt động khoa học tổng thể của trường. Chính điều này là động lực giúp học viên cao học, những người được đào tạo để bước chân vào con đường nghiên cứu khoa học có môi trường, có kinh phí để thực hiện đề tài mang tính ứng dụng và đáp ứng mục tiên, tầm nhìn và chiến lược chung 
của nhà trường. Đây cũng chính là điểm mạnh, điểm nổi trội của chương trình đào tạo Thạc sĩ CTXH so với các chương trình đào tạo của các trường khác.

Tóm lại, với chuẩn đầu ra năm 2020-2022, bản thân tác giả cho rằng có nhiều cải tiến: Chương trình tích hợp các nội dung, hướng đến mục tiêu cụ thể, có tiêu chí đánh giá cụ thể (Rubric đánh giá), phương thức, nội dung môn học được thiết kế tập trung hướng đến mục tiêu, tầm nhìn, chiến lược mà chương trình đào tạo đã đề ra.

\section{Kết luận}

\section{Đối với ngườ học}

Xây dựng chương trình đào tạo thạc sĩ CTXH theo chuẩn CIDO là một phương pháp tiếp cận mới, mang tính khoa học.

Chuẩn đầu ra rõ ràng và lượng hoá tương đối qua việc đánh giá học viên có tiêu chuẩn rõ ràng đối với khoa học xã hội nói chung, ngành CTXH nói riêng là bước tiến lớn, đáp ứng tiêu chí hướng đến sự công bằng trong việc đánh giá kết quả học tập của người học. Thể hiện sự bình đẳng giữa người dạy và người học mà phương pháp giáo dục truyền thống chưa đáp ứng được.

Chương trình đào thạo thạc sĩ CTXH mở ra nhiều cơ hội cho người học trong thực hành, thực tế tại nước ngoài. Tham gia nghiên cứu đứng chủ nhiệm đề tài cá nhân. Tham gia vào hoạt động nghiên cứu khoa học như một thành viên của nhà trường.

Người học chủ động nghiên cứu nội dung, chương trình học qua công nghệ thông tin (Elearning), thể hiện bước đầu tiên trong quá trình hội nhập với hiện đại hoá và toàn cầu hoá.

\section{Đối với người dạy}

Giảng viên chuyên nghiệp hơn trong quá trình thiết kế đề cương chi tiết và bài giảng cho học viên. Giảng viên chỉnh chu và đầu tư bài giảng hơn vì mức độ đầu ra cần được thiết kế và đáp ứng với mục tiêu chung của chương trình đào tạo.

\section{Đối với nhà truò̀ng}

Thiết kế chương trình theo chuẩn $\mathrm{CDIO}$, đáp ứng tầm nhìn, chiến lược của nhà trường. Góp phần vào thành công chung của nhà trường đáp ứng mục tiêu đào tạo chung của nhà trường là thể hiện trách nhiệm của chương trình đào tạo thạc sĩ CTXH đối với xã hội.

Nói tóm lại. Sự thay đổi trong phương pháp tiếp cận thiết kế chương trình theo chuẩn CDIO là một bước tiến quan trọng và nhà trường đã rất nhanh chóng nắm bắt xu hướng của xã hội định hướng chương trình đào tạo thực hiện. Tuy nghiên, việc chuẩn hoá, lượng hoá mục tiêu, đầu ra của chương trình đào tạo này cũng đặt ra nhiều thách thức trong quá trình thực hiện đào tạo học viên, đòi hỏi sự gắn kết giữa giảng viên, học viên, và lãnh đạo chương trình, viện đào tạo sau đại học, phòng nghiên cứu khoa học, các cơ sở thực hành thực tập. Sự gắn kết này còn tuỳ thuộc vào mô hình quản trị của Viện đào tạo nằm ngoài nội dung bài viết này. 


\section{Tài liệu tham khảo}

[1] Phạm Tất Dong (2012), Xây dụng mô hình xã hội học tập ở Việt Nam, NXB: Dân Trí

[2] Trần Khánh Đức (2010), Giáo dục và phát triển nguồn nhân lục trong thế kỷ XXI, NXB: Giáo dục Việt Nam.

[3] Lê Bảo Lâm, Nguyễn Hữu Từ (2013), Hội thảo nâng cao chất luợng giáo dục đại học, NXB: Thanh Niên.

[4] Edward F. Carwley và đồng nghiệp, Hồ Tất Nhật và Đoàn Thị Minh Trinh dịch (2009), Cải cách và xây dựng chuơng trình đào tạo kỹ thuật theo phương pháp tiếp cận CDIO, Tái bản lần 1, NXB: ĐHQG TPHCM.

[5] Đoàn Thị Trinh, và đồng sự (2012), Thiết kế và phát triển chuoong trình đào tạo đáp úng chuẩn đầu ra, NXB: ĐHQGTPHCM.

[6] Chương trình đào tạo thạc sĩ CTXH năm 2020-2022 